\title{
HEALTH GEOGRAPHY
}

\section{Medical Tourism: A History and Overview of the Industry and the Case Study of Addiction Recovery in Spain Kazimir Haykowsky}

\begin{abstract}
This paper focuses on the emerging global market in medical tourism. The industry continues to expand and become increasingly profitable with greater popular support. This paper conveys the findings of a literature review on the origins, history and contemporary development of the industry. It explores the rationale and access of the medical tourist, and the purported benefits and costs to involved parties including patients, caregivers, citizens and governments. Ultimately it reveals that this phenomenon leads to lower costs, better care, discretion and leisure benefits to wealthy and mobile international clients while reducing available resources and quality of care for residents of host countries, which are mostly low and middle income countries and potentially costing source countries in aftercare. This paper examines the case study of international treatment for addiction in Spain and analyze two websites advertising the treatment for their use of promotional tactics, the importance of place and the relevance of Wilbert Gesler's therapeutic landscape concept in marketing services. This reveals that international mobility allows businesses to profit from permissive legal environments and popular therapeutic landscapes abroad.
\end{abstract}

\section{INTRODUCTION}

Medical tourism is an emerging phenomenon in contemporary, globalized healthcare that warrants close scrutiny. The industry continues to expand and become increasingly profitable with greater support from a broad range of society. This paper will convey the findings of a literature review on the origins, history and contemporary development of the industry. It will explore the rationale and access of the medical tourist, and the purported benefits and costs to involved parties including patients, caregivers, citizens and governments. Finally, this paper will examine the case study of international treatment for addiction in Spain and analyze two websites advertising the treatment for use of promotion tactics and the importance of place and Wilbert Gesler's therapeutic landscape concept in marketing services.

\section{THE HISTORY OF MEDICAL TOURISM}

Medical tourism is described in Johnston et al. (2012, p.1) as the "intentional movement of patients across international borders to seek medical care that has been privately purchased and arranged for." Travel for health or medical reasons has a long history of practice, and the concept of traveling to remote, natural settings and 'taking the waters' became common by the 18th century" (Connell, 2006, p.1093). It was believed by “[p]hysicians, scientists, policy makers, and patients... that high-elevation mountain climates worldwide would help cure the disease" (Carey, p.795). But these locations were never simply wild or left in their natural state and the importance of the built environment around these sites is equally important as the remoteness and setting of the healing site. This might include spas, treatment facilities, hotels, restaurants and walking paths to name a few. More recent health tourism has focused on health practices rooted in places of 
perceived healing qualities with tourists traveling "in search of yoga and meditation." (Connell, 2006, p.1093). Turner points out that "Hot springs, spas, desert retreats, seaside resorts and mountain sanatoriums have long attracted clients willing to journey in search of treatment." (2007, p.2306).

Wilbert Gesler introduced the concept of "therapeutic landscapes" describing "landscapes associated with treatment or healing" (1991, p.735-6) and notes that "[t]here is a long tradition that healing powers may be found in the physical environment, whether this entails materials such as medicinal plants, the fresh air and pure water of the countryside, or magnificent scenery" (1991, p.736). Gesler (1991) suggests that anything from the physical features of the landscape, the built environment, the social meaning, symbolism, ceremony and daily, mundane activities surrounding the landscape can contribute to its healing and therapeutic qualities.

\section{CONTEMPORARY MEDICAL TOURISM}

Medical tourism has rapidly developed from a niche market to an industry in its own right "where people travel often long distances to overseas countries to obtain medical, dental and surgical care while simultaneously being holidaymakers, in a more conventional sense" (Connell, 2006, p.1094). A number of factors have played into the development of this industry. The advent and ubiquity of the internet now means that patients can connect with treatment facilities around the globe as easily -or easier- than a local clinic. Horowitz et al. (2007, p.4) point out that technology "enables potential medical tourists to investigate and arrange healthcare anywhere in the world from their home computer directly or with the advice and assistance of a medical tourism agency." These medical tourism agencies that "bridge the gap between clients and caregivers" (Turner, 2007, p.2306) have become an increasingly important part of the industry.

Countries are beginning to see the economic importance of the industry and are, in many cases, doing what they can to promote it. Medical tourism has become a considerable source of income for Low and Middle Income Countries (LMICs). Singapore, for instance "is seeking to attract 1 million patients by 2012, which would generate US $\$ 1.8$ billion in revenues, create at least 13,000 jobs (Ai-Lien, cited in Connell, 2006, p.1099). It is estimated that tourists in Thailand "spent US\$1.6 billion in 2003, while medical tourists in South Africa were estimated to spend between US\$30-40 million in the same year." (Taffel, cited in Connell, 2006, p.1098) Markets in these countries respond to demand from mobile and affluent health-seekers and they do so in unique ways.

\section{REGIONALISM AND SPECIALIZATION IN MEDICAL TOURISM}

With increasing competition in a globalized marketplace, LMICs are beginning to compete for the lucrative industry and the dollars of patients from more high income countries. Hanefeld et al. point to a "regional dimension to medical tourism" (2014, p.211) wherein particular countries serve as common destinations for particular nationalities or as centers of treatment expertise in a particular field. Cuba, for instance "specialises in skin diseases and Antigua in dentistry" (Connell, 2006, p.1095). Thailand has been a longstanding powerhouse in medical tourism "because it specialised in sex change operations, and later moved into cosmetic surgery" (Connell, 2006, p.1095). As one might travel to Cambodia to see Angkor Wat they might also travel to the country for a root canal, or both. 


\section{MOTIVATIONS TO TRAVEL}

The prospect of tourism in conjunction with receiving medical care can be a powerful pull factor for international patients considering medical tourism. Private hospitals are well aware of this and often "offer packages designed to attract wealthy foreign patients" (Ramesh, 2005, para.9). Connell (2006, p.1094) points out a number of branded tours including "Surgeon and Safari (South Africa) ... Antigua Smiles...Gorgeous Getaways in Australia" while one Bombay hospital promotes their treatment with the slogan "“open your new eyes on the beach at Juha' (some $30 \mathrm{~km}$ to the north)" (Connell, 2006, p.1098).

Affordability is another key concern in choosing medical tourism. Connell points out that "[e]ven with airfare, the cost of going to India for surgery can be markedly cheaper, and the quality of services is often better than that found in the United States and UK" (Connell, 2006, p. 1093). Prices in India are some of the most affordable in the world "with prices as low as $10 \%$ of those in the United States" (Horowitz et al., 2007 p.5) and where "the professional liability insurance premium for a surgeon... is 4 percent of what it is in New York" (Horowitz \& Rosenweig, 2007, p.26).

Avoiding wait times, accessing treatment not covered by public or insured health care and the discretion of travel are also major pull factors. For citizens of countries with a national healthcare system - known for long wait times - the "major reason to choose offshore medical care is to circumvent delays associated with long waiting lists" (Horowitz et al., 2007, p.4). Furthermore, these national healthcare systems seldom "pay for cosmetic surgery and similar type services" (Horowitz et al., 2007, p.4). Certain forms of treatment may be unavailable for more political or public safety reasons. For instance, "[a]bortions are banned in several countries... [and] In Britain, for example, health authorities are usually unwilling to countenance stomach stapling for patients if they are aged less than 18" (Connell, 2006, p.1097). Domestic laws may also be restrictive on treatment availability, as with laws in many Arab and Gulf states against the use of alcohol and drugs and the consequent restriction on addiction treatment centers in those countries. Discretion can be another reason to seek treatment abroad, as some procedures may be frowned upon by friends, family and society. Horowitz and Rosenweig (2007, p.25) suggest that travel to a foreign country can offer "privacy and confidentiality for patients undergoing plastic surgery, sex change procedures and drug rehabilitation" and the possibility of recuperation on a beach is an added benefit.

\section{RISKS AND COSTS}

Medical tourism might seem to be the perfect option for the affluent and mobile global citizen, but as with all good things, there is a dark side. First of all, there may be costs to patients. Aside from the possibility of Joint Commission International accreditation - which is not held by most institutions - facilities are considered based on private quality assurance, testimonials and overseas credentials. Studies cited in Hanefeld et al. (2014, p.413) show a "vacuum in regulation, with no one specific regulator or quality assurance standard in place, but rather a number of private companies offering quality assurance through affiliation."

This may lead to costs for the home medical system as poor quality surgery, complications and infection are dealt with upon the patient's arrival home. In the UK, "a survey conducted by the British Association of Plastic, Reconstructive and Aesthetic Surgeons... found that 37\% of 
respondents had seen patients in the NHS with complications from overseas surgery" (Hanefeld et al., 2014, p.413).

However, the greatest costs may be to the host countries. With hospitals in countries like Thailand, India and Mexico competing for international dollars, domestic patients may no longer be able to access care in their own countries, or be subject to a lower standard of care. Hanefeld et al., (2014, p.414) support the notion that "medical tourists with their higher purchasing power are likely to increase the cost of health services and lessen access in the public sector." With increasing public investment in these clinics, the training of medical staff and the procurement of medical equipment there is less public funding for clinics accessible to citizens who already "lack access to basic health care and social services" (Turner, 2007, p.2320). Ravi Duggal, quoted in Ramesh (2015, para.20) says that "We have doctors but they are busy treating the rich in India".

\section{ADDICTION RECOVERY IN SPAIN}

This second section will focus on the case study of two treatment facilities for addictions in Spain, and their inpatient treatment: Ibiza Calm and Camino Recovery. The home page of the Ibiza Calm website shows contact numbers for both the UK and Spain, and includes translations in Spanish, English and Dutch. The website is beautifully laid out (Fig. 1), with immaculate photos and videos depicting a sunny, warm, tropical environment, though no photos include people. The clinic boasts an intimate environment with "no more than 10 patients at a time" (2016, Point 1). All of the information on the home page focuses on the quality of treatment, with individualised care plans including "individual and group therapy, educational lectures, meditation, yoga and exercise" (2016, Point 2). A video on the home page waxes poetic about the beauty and magical quality of the island of Ibiza, saying "we have 300 plus blue sky days a year. I defy anyone to say that isn't going to be good for you" (2016, 0:25). The site emphasizes the clinic as a place to "start the process of physical, emotional and mental recovery in beautiful surroundings" (Home page, 2016, Para.3) The "About the Clinic" page emphasizes that they have "created a supportive and restful space" (Ibiza Calm, 2016, Para.2) and that the clinic is a "short drive from several beautiful villages and beaches" and provides "ample space for walking, relaxation and contemplation" (Ibiza Calm, 2016, Para.3)

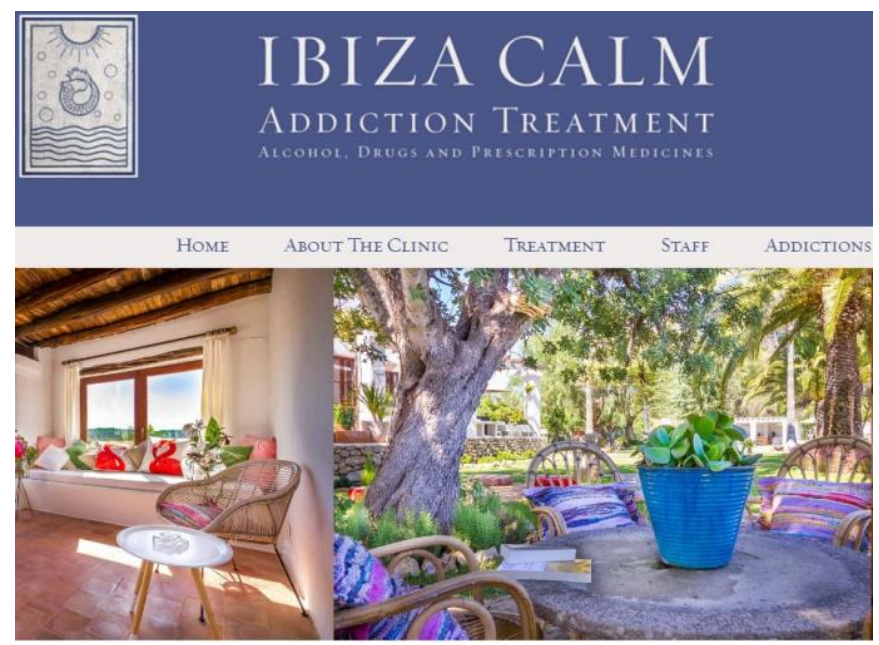

Fig 1: Attractive scenery on the Ibiza Calm website. [http://ibizacalm.com/contact/] 2016. 
The "Treatment" page does not go into great detail but outlines the wide range of addictions treated, the treatment process and special attention for bipolar disorder. The website places a strong emphasis on the range of treatments available and the quality of treatment offered. The page also notes that "We admit English speaking patients from all over the world" and "We pick everyone up from the airport" (Ibiza Calm, 2016, Para.10). The "Team" page boasts an international team with staff primarily from the UK and some practitioners from the Netherlands and Spain. The location of this clinic is ironic, being on the island of Ibiza better known for "serried, concrete terraces of superclubs with their ranks of hands-aloft maniacs chanting the names of ageing DJs" (Armstrong, 2006, Para.2) and where "the lure of illicit substances, to consume or sell, is constant" (Reidy, 2013, Para.6). This is, to say the least, a unique place for addiction recovery.

The home page of Camino Recovery introduces itself as being "In a tranquil retreat on Spain's Andalusian coast" (2014, Para.1) and "Drawing on 80 years of combined, multidisciplinary expertise" (Para.2). Navigating to the "Residential Addiction Treatment" page it focuses first on the "privacy and seclusion of our recovery centre" (Para.1) and the range of disorders treated there by a "multi-disciplinary team" (Para.4). The first major heading invites prospective patients to "Start every day on the beach... just a few minutes' walk from the recovery centre" (Para.6). Treatment at the facility focuses on therapy through the morning and "yoga, massage and acupuncture as well as regular visits to the local gym and spa" in the afternoon (Para.6) However, the aesthetic and environmental aspect of treatment in Spain is not textually emphasized. The focus on this page is on the range of treatments available, from group therapy, free aftercare, family support and specialist treatment like "Eye movement desensitisation and reprocessing (EMDR) [and] Equine assisted psychotherapy (EAP)" (Para.16). As with Ibiza Calm, the focus here is on the range and quality of treatment and not on the therapeutic effects of the landscape. In a video interview with director Lavender, he describes it as "a small center, it's eight beds" (2011, 0:25) and it is clear that it is an exclusive facility. Later in the interview he states that he and his wife "were looking at the Mediterranean as a place to, possibly, retire" $(2011,2: 20)$ when they decided to open the clinic in Malaga, Spain on the Mediterranean coast. In another interview with Lavender, a full third of the video focuses on the environs and he states that "We think that detoxing... in the sun is better than a cold, wet climate" $(2012,4: 29)$.

The "Team" page boasts international practitioners with a director from the United States and General Practitioners and therapists from the UK. None of the treatment staff are natives of Spain which further emphasizes the international focus of the clinic. It's evident that it is not Spanish practitioners or methods that are sought after, but something about the place itself.

Very interestingly, the website has an entire page on "International Treatment" with uncredited articles on a handful of gulf states that begin with a background on mental health treatment and statistics in the country followed by an endorsement for treatment at Camino Recovery Center (Fig. 2). This shows the primarily international focus of the clinic, hosted in Spain by English and American practitioners and attracting patients from the Persian Gulf. This is striking because of the existence of "strict laws forbidding drugs and alcohol in Saudi Arabia" (2014, Para.1) and most other gulf states. These laws make the establishment of an addiction recovery center basically impossible. A quick Google search of the term "addiction recovery in Saudi Arabia" turns up four ads for UK, Thai and Canadian treatment centers and the first two non-advertisement links are for Camino Recovery in Spain. As a result of the lack of domestic 
treatment available this creates a perfect market for medical tourism abroad. Because of the high cost of international travel and of treatment in these beachside resorts, treatment is likely only available to the wealthiest strata of the population of the gulf states.

The article entitled "Treatment for Depression Dubai" states that "Because of the continuing state of development of the Dubai mental health care system and the negative stigma that surrounds conditions such as depression, many look overseas for assistance" (2014, Para.4). It goes on to state that some treatments offered "cannot be found in the UAE" (Para.10) and that upon arrival "one of our personal drivers will pick you up at the airport and bring you straight to our seaside retreat. Here, you will check into Camino Recovery as you would a hotel" (Para.11). The "Contact" page includes an offer to help with travel arrangements and the UK phone numbers and their partnership with The Renewal Center in London indicates their strong patient connection with the UK.

\section{Drug \& Alcohol Rehab Kuwait}
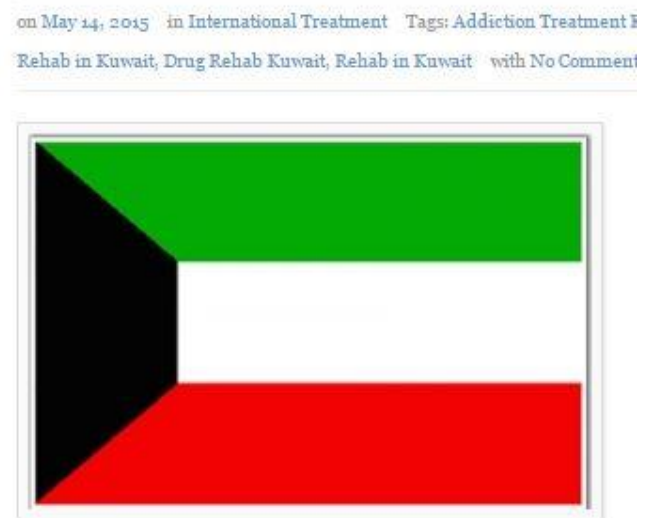

\section{Treatment for Trauma Oman}

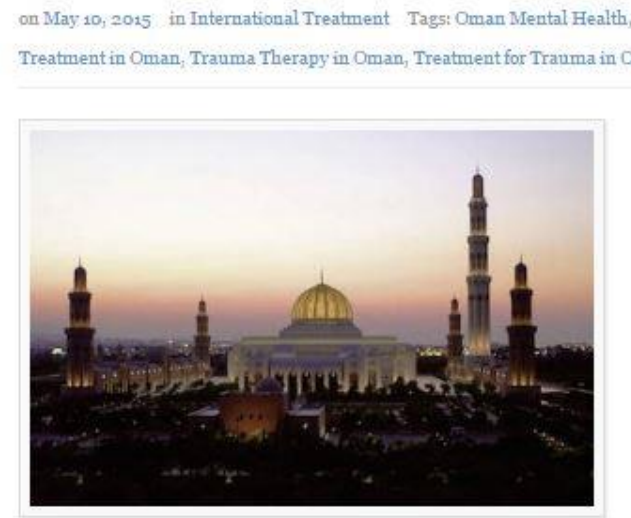

Fig 2: "International treatment at Camino" Camino Recovery

[http://www.caminorecovery.com/category/international-treatment], 2014 


\section{ADVERTISING ANALYSIS}

These case studies are a departure from the norm of medical tourism discussed in the first section as these treatment facilities are located in a high-income country, rather than a LMIC like India, Thailand or Mexico where more physical treatments are sought. The mental health nature of the treatment differentiates these facilities. It was clear in the advertising of both clinics that they are exclusive and likely very expensive, due to the limited number of beds available for treatment, though prices were explicitly not listed and available only by calling for a consultation.

The importance of leisure activities was clear in the advertising of both clinics, but as mentioned it took a secondary and primarily aesthetic place behind the emphasis on range and quality of treatment. Both websites used visual messaging and visual marketing to emphasize the therapeutic aspects of the Spanish beach setting. Spain is already a popular tourist destination for the British so they may have deemed it unnecessary to over-emphasize the scenery and landscape. That said, there are many instances of visual emphasis of the environment. The promotional video for Ibiza Calm first explicitly identified climate and weather as an undisputed positive factor in recovery from addiction. Before mentioning any specific treatments or procedures the video contends that on the island "you seem to feel a magic, you seem to feel like there's something about the place that's actually hard to articulate" (2016, 0:14). The site emphasizes how close the clinic is to beaches and local tourist towns and the importance of having a "supportive and restful space" (Ibiza Calm, 2016, Para.2). Ibiza is globally renowned as a tourist destination and Money Pacers calls it a "billionaires playground and vacation home to some of the most wealthy people on the planet" (Briscoe, 2015, Para.1).

Materials on the Camino Recovery site allude more directly to the benefits of the environment to treatment. The founding director, Lavender, states in a promotional video that it is his ideal location to retire, and that was a motivating factor in choosing the site: it is a place where he would ideally like to vacation and where he believes people will want to be treated. It is also fascinating to note just how blurred the lines are between hospital and hotel, treatment and leisure when the website says "Here, you will check into Camino Recovery as you would a hotel" (Camino Recovery, "Treatment for Depression Dubai", 2014, Para.11). In these facilities, patients are treated as guests and treatment and leisure are given almost equal weight of importance.

The visual marketing used on these sites demonstrates the power of Wilbert Gesler's therapeutic landscape concept. He describes that "[o]ne particular aspect of the physical environment that has been a source of healing for many societies is water" (1991, p.737), which is clearly emphasized on both the Ibiza Calm and Camino Recovery websites through their images of white beaches, crystal-clear ocean water and promises of walking or swimming before a day of treatment. Imagery on the sites also emphasizes the built environment of care, with white-stuccoed Spanish manors draped in deep purple and orange cloth, light wood textures, wide windows allowing lots of natural light, and a human-scale, traditional built form giving a feeling of ease, luxury and comfort. The symbolic environment is also emphasized in these images, with many rousing scenes of rising suns, open notebooks, open windows, empty chairs waiting for patients, plates of hot food and bowls full of fruit. All of these suggest a rich, warm and welcoming environment just waiting for the patient to come and heal. Routine is also emphasized in verbal marketing, suggesting a regimen of physical activity and yoga sessions, which lend themselves also to the spiritual environment. The video on the main page of the Ibiza Calm website suggests 
that "some people describe the main house as a chapel" (2016, 0:56) driving home the sense of place being cultivated for patients and in patient's minds so that the landscape is not just one of discrete treatment -like a hospital or clinic- but a place of habitual and intentional healing.

In both cases, facilities were set up by British expatriates and targeted their advertising at other citizens of the UK. It was interesting to note that Camino Recovery specifically targeted patients in the Gulf states like Dubai, Bahrain and even Saudi Arabia. The Camino Recovery website even states in its "Treatment for Depression Saudi Arabia" article that "the mental health field in Saudi Arabia still has a long way to go to catch up to the West" (2014, Para.1). Their article on "Drug and Alcohol Rehab Saudi Arabia" notes that in gulf states there is "stigma attached to drug or alcohol abuse and that most never talk about their addiction" (2014, Para.5). This speaks to the motivating factor of discretion and privacy when seeking out mental health treatment abroad. As suggested by Horowitz and Rosenweig (2007, p.25) treatment abroad can offer "privacy and confidentiality for patients undergoing... drug rehabilitation."

This discretion is particularly valuable in home countries where drug and alcohol consumption are severely punished and where median incomes are relatively high, like Saudi Arabia and Oman. Countries that strongly criminalize drug and alcohol use are unlikely to have robust drug treatment programs, as evident in the Camino Recovery article stating that rehab programs "cannot be found in the UAE" (2014, Para.10), forcing patients to seek treatment outside their national borders. This creates the perfect conditions for medical tourism to arise. For British citizens and English speakers, the attraction of being treated in your native language in a location far from home is clearly very appealing, as both of these clinics draw their client base primarily from the UK.

The main cost of seeking this treatment to patients would be financial. It is unlikely that mental health treatment in Spain is significantly undercutting employment in the UK or a gulf state as each of these facilities accept only eight or ten patients at a time. Their exclusivity likely makes them a very costly option for patients and families. It may also be challenging for patients to find ongoing care in their home country if they are accustomed to isolated treatment environments on the beach in Spain, though these clinics do offer free follow-up care. Otherwise, their home medical system may not be able to help them in the same way and they may fall into relapse without a local support network for themselves and their families.

In both cases, the fact that facilities were set up by British expatriates and advertised specifically to other British citizens made these cases unique from earlier research. Earlier findings suggested that medical tourism was primarily driven by domestic industry and even by domestic governments as in the case of the government of Singapore hoping to "attract 1 million patients... and even restore economic growth" (Ai-Lien, cited in Connell, 2006, p.1099). Here instead, investment and expertise from outside of Spain was used to set up clinics there, suggesting the primacy of the setting and scenery - not the capacity of the domestic treatment industry - in the selection of the site. It would be interesting to carry out further research on the impact and influence of foreign investment and expatriate-owned businesses in the medical tourism industry in both high income and LMICs. This research could follow the flow of income from international treatment sites to see where the profit and benefits are experienced. It could also identify if expatriate businesses have greater levels of trust from citizens of a common origin, offering them 
a competitive advantage in attracting international patients.

\section{CONCLUSION}

It is clear from this literature and advertising review that health tourism has evolved dramatically from its origins into the international industry that it is today. The industry has become the purview of both enterprising national and international business and national governments seeking to boost GDP and derive more diverse sources of income in a globalized, fluctuating market. However, the economic stability can come with costs to quality of care in home countries, risks to patients and cost to home medical systems. The lure of beautiful sceneries can attract patients and practitioners alike, not to mention the low costs of labour, drugs, equipment and government subsidy. As evident in the analysis of the Ibiza Calm and Camino Recovery websites, medical tourism also allows international practitioners access to more appealing legal environments and therapeutic landscapes in which to market and practice their profession. The international clinical geography created by this free movement of labour, patients and money may promise democratization and competitiveness in health provision, but parallel fault lines of inequality of income and access to care show through.

\section{REFERENCES}

Armstrong, S. (2006, July 1) Ibiza unplugged. The Guardian. Retrieved from https:/www.theguardian.com/travel/2006/jul/01/balearicislands.filminspiredtravel.spain

Briscoe, D. (2015, June 26) Ibiza, Spain - A Billionaire's Playground. Money Pacers. Retrieved from https://moneypacers.com/2015/06/26/ibiza-spain-a-billionaires-playground/

Camino Recovery. (2014). Retrieved from http://www.caminorecovery.com/

Carey, M. (2014). Climate, Medicine, and Peruvian Health Resorts. Science Technology \& Human Values, 39(6), 795818.

Connell, J. (2006). Medical tourism: Sea, sun, sand and . . surgery. Tourism Management, 27(6),1093-1100.

Gesler, W.M. (1982). Therapeutic landscapes : medical issues in light of the new cultural geography. Social Science \& Medicine, 34(7), 735-746.

Lavender, D. (2011, January 18). Don Lavender from Camino Recovery. [Video file]. Retrieved from https://www.youtube.com/watch?v=ZJQmdTNPOeE

Lavender, D. (2012, December 22). Welcome to Camino Recovery. [Video file]. Retrieved from https://www.youtube.com/watch?v=heakEXbfCrU

Hanefeld, J., Smith, R., Horsfall, D., \& Lunt, N. (2014). What Do We Know About Medical Tourism? A Review of the Literature With Discussion of Its Implications for the UK National Health Service as an Example of a Public Health Care System. Journal Of Travel Medicine, 21(6), 410-417.

Horowitz, M. D., Rosensweig, J. A., \& Jones, C. A. (2007). Medical tourism: globalization of the healthcare marketplace. Medgenmed: Medscape General Medicine, 9(4), 33.

Horowitz, M. D., \& Rosenweig, J. A. (2007). Medical Tourism -- Health Care in the Global Economy. Physician Executive, 33(6), 24-30.

Ibiza Calm. (2016). Retrieved from http://ibizacalm.com/

Ibiza Calm S.L. (2016, August 18). Ibiza Calm.com. [Video file]. Retrieved from https://vimeo.com/179308627

Johnston, R., Crooks, V., \& Snyder, J. (2012). "I didn't even know what I was looking for": A qualitative study of the decision-making processes of Canadian medical tourists. Globalization And Health, 8.

Ramesh, R. (2015, February 1). This UK patient avoided the NHS list and flew to India for a heart bypass. Is health tourism the future?. The Guardian. Retrieved https://www.theguardian.com/uk/2005/feb/01/health.india

Reidy, T. (2013, August 17). Ibiza: 'Nothing is innocent and dealing is normal. The Guardian. Retrieved from https://www.theguardian.com/world/2013/aug/17/ibiza-drugs-dark-side

Turner, L. (2007). 'First World Health Care at Third World Prices': Globalization, Bioethics and Medical Tourism. Biosocieties, 2, 303-326. 